\title{
Codes in the itineraries of the planets of the Solar System
}

\author{
Lutvo Kurić \\ Institute of Economics, University of Sarajevo, Trg Oslobođenja 1, Sarajevo, \\ Bosnia and Herzegovina \\ E-mail address: lutvokuric@yahoo.com
}

\begin{abstract}
Cosmos can be viewed from the perspective of the most advanced program, cyber and information systems and laws. Digital language Cosmos has a myriad of constants and variables, matrices, functions, vectors and determinants, which are coded information about the creation and functioning of our physical world in which we live. These are: Planetary orbits, Orbital Motion, Orbital planes, Orbital period Specifying orbits, Orbital perturbations, astrodynamics, Earth orbits, etc. The heavenly bodies move along a particular path. They have their own Perihelion and Aphelion. They have to move much on that path because the cosmic laws of the digital language does not allow them to move along another path. There is no dilemma and can not be. Evidence that follow testify and confirm that there is indeed a universal language for an exact description of which can be used systems theory and cybernetics.
\end{abstract}

Keywords: Solar system; planetary code; orbital code; cosmic codes

\section{INTRODUCTION}

Research results that we obtained show that the process of sequencing all processes in the Cosmos, without a single exception, is conditioned and determined not only physicochemical, but cybernetic-informational laws. Readers of this paper we will give exact evidence that there is a universal language for the description of which can be used systems theory and cybernetics, and which operates according to specific rules. Galileo once said that the great book of nature is written in mathematical symbols. And he was right. In this book there is a myriad of algorithms, matrix codes and analogue codes, primary and secondary values, odd and even size, determinants, main memory, internal memory and additional memory that can accept the unit of information that is confidential and that we give available when you need it. Galileo once said that the great book of nature is written in mathematical symbols. And he was right. In this paper, there is a myriad of algorithms, matrix codes and analogue codes, primary and secondary values, odd and even size, determinants, the main memory, internal memory and additional memory that can accept information unit that is kept and that we give available when you need it. 


\section{RESULTS}

The potential effects of physical and Orbital characteristics, as well as cybernetic and information principles, on the atronomical basis of Solar System are also investigated. This paper discusses new methods for developing astronomy technologies, in particular more advanced digital technology based on programming, cybernetics, and informational laws and systems, and how this new technology could be useful in astronomy, bioinformatics and other natural sciences.

\begin{tabular}{|c|c|c|c|c|c|c|c|}
\hline \multicolumn{8}{|c|}{ Perihelion and Aphelion planets of the Solar system } \\
\hline Merkur & Venus & Earth & Mars & Jupiter & Saturn & Uranus & Neptune \\
\hline Perihelion & Perihelion & Perihelion & Perihelion & Perihelion & Perihelion & Perihelion & Perihelion \\
\hline 46001200 & 107476259 & 147098290 & 206669000 & $\overline{740573600}$ & 1353572956 & 2748938461 & 4452940833 \\
\hline 1 & 2 & 3 & 4 & 5 & 6 & 7 & 8 \\
\hline $\begin{array}{c}\text { Merkur } \\
\text { Aphelion }\end{array}$ & $\begin{array}{c}\text { Venus } \\
\text { Aphelion }\end{array}$ & $\begin{array}{c}\text { EARTH } \\
\text { Aphelion }\end{array}$ & $\begin{array}{c}\text { Mars } \\
\text { Aphelion }\end{array}$ & $\begin{array}{c}\text { Jupiter } \\
\text { Aphelion }\end{array}$ & $\begin{array}{c}\begin{array}{c}\text { Saturn } \\
\text { Aphelion }\end{array} \\
\end{array}$ & $\begin{array}{r}\text { Uranu } \\
\text { Aphelic }\end{array}$ & $\begin{array}{c}\text { Neptune } \\
\text { Aphelion }\end{array}$ \\
\hline 69816900 & 108942109 & 152098232 & 249209300 & 816520800 & 151332578 & $\overline{3004419}$ & 4553946490 \\
\hline 1 & 2 & 3 & 4 & 5 & 6 & 7 & 8 \\
\hline
\end{tabular}

\section{1. Astronomical progression}

\section{Example:}

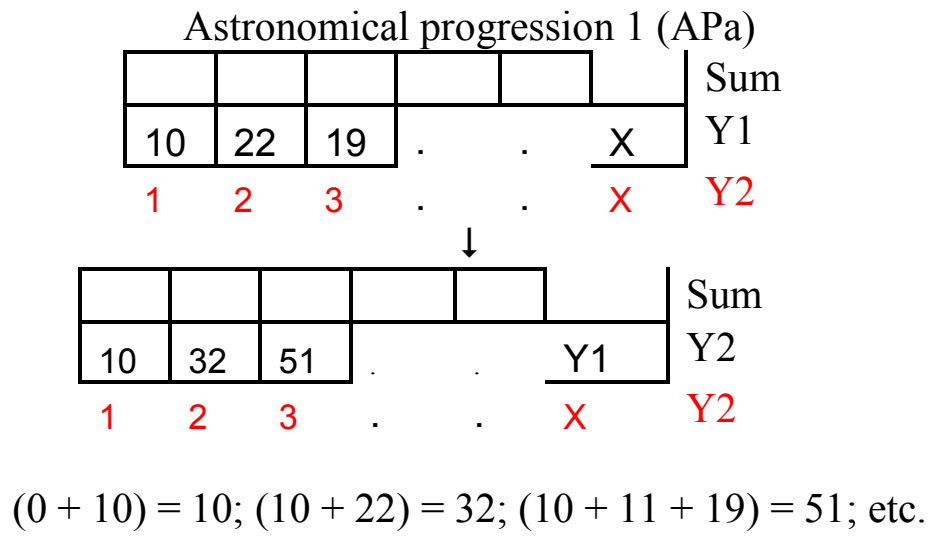

Figure 1. Schematic representation of the astronomical progression from $\mathrm{X}$ to 1 .

\section{Step 1}

$$
\begin{gathered}
\mathrm{AC}_{1}=10 ; \mathrm{AC}_{2}=22 ; \mathrm{AC}_{3}=19 ; \ldots \mathrm{AC}_{\mathrm{x}}=17 \\
{\left[\mathrm{AC}_{1}+\left(\mathrm{AC}_{1}+\mathrm{AC}_{2}\right)+\left(\mathrm{AC}_{1}+\mathrm{AC}_{2}+\mathrm{AC}\right)_{3} \ldots,+\left(\mathrm{AC}_{1}+\mathrm{AC}_{2}+\mathrm{AC}_{3} \ldots,+\mathrm{AC}_{\mathrm{x}}\right)\right]=\mathrm{S}_{1}} \\
\mathrm{AC}_{1}=\mathrm{APa} 1=10 ; \\
\left(\mathrm{AC}_{1}+\mathrm{AC}_{2}\right)=(10+22)=\mathrm{APa} 2=32 ;
\end{gathered}
$$




$$
\begin{aligned}
& \left(\mathrm{AC}_{1}+\mathrm{AC}_{2}+\mathrm{AC}_{3}\right)=(10+22+19)=\mathrm{APa} 3=51 ; \\
& \left(\mathrm{AC}_{1}+\mathrm{AC}_{2}+\mathrm{AC}_{3} \ldots,+\mathrm{AC}_{\mathrm{x}}\right)=\mathrm{APax} \\
& \mathrm{APa} 1,2,3, \mathrm{n}=\text { Astronomical progression 1,2,3,n } \\
& \left.\left.\left[\mathrm{APa}_{1}+\mathrm{APa}_{2}+\mathrm{APa}_{3}\right) \ldots,+\mathrm{APax}\right)\right]=(10+32+51 \ldots,+\mathrm{X})=\mathrm{S}_{1} \text {; }
\end{aligned}
$$

\section{Example:}

Astronomical progression $2(\mathrm{APb})$

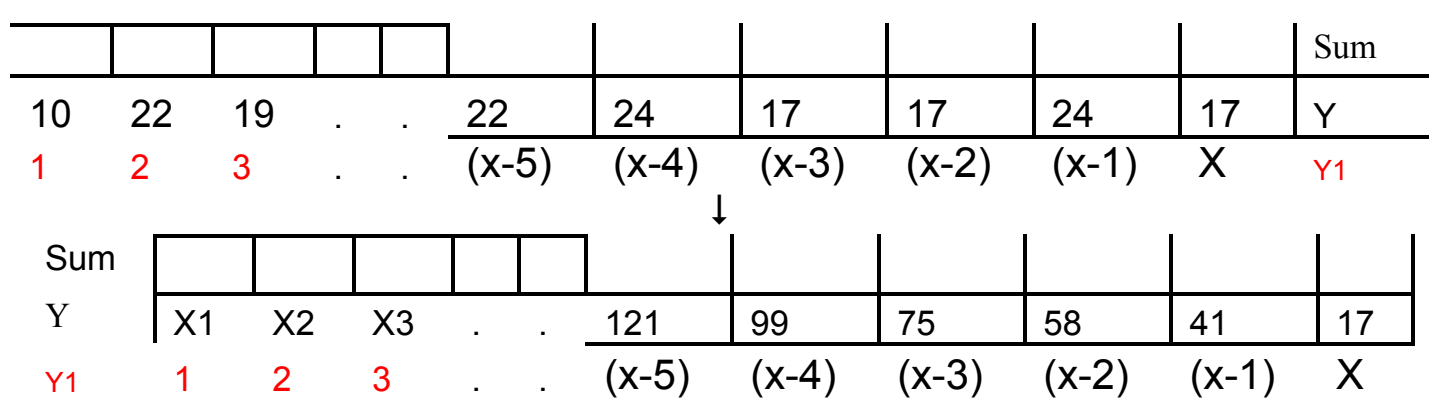

$(0+17)=17 ;(17+24)=41 ;(17+24+17)=58 ;$ etc.

Figure 2. Schematic representation of the astronomical progression 2 from $\mathrm{X}$ to 1 .

$$
\begin{aligned}
& \text { Step } 2 \\
& \mathrm{AC}_{\mathrm{x}}=17 ; \operatorname{Ac}(\mathrm{x}-1)=24 ; \mathrm{AC}_{(\mathrm{x}-2)}=17 ; \ldots \mathrm{AC}_{1}=10 ; \\
& {\left[\mathrm{AC}_{\mathrm{x}}+\left(\mathrm{AC}_{\mathrm{x}}+\mathrm{AC}(\mathrm{x}-1)\right)+\left(\mathrm{AC}_{\mathrm{x}}+\mathrm{AC}_{(\mathrm{x}-1)}+\mathrm{AC}_{\mathrm{xx}-2)}\right) . .,+\left(\mathrm{AC}_{\mathrm{x}}+\mathrm{AC}_{(\mathrm{x}-1)}+\mathrm{AC}_{(\mathrm{x}-2) \ldots,}+\mathrm{AC}_{1}\right)\right]=\mathrm{S}_{2}} \\
& \mathrm{AC}_{\mathrm{x}}=\mathrm{APb}_{\mathrm{x}}=17 \\
& \left(\mathrm{AC}_{\mathrm{x}}+\mathrm{AC}_{(\mathrm{x}-1))}=(17+24)=\mathrm{APb}_{\mathrm{x}}=41 ;\right. \\
& \left(\mathrm{AC}_{\mathrm{x}}+\mathrm{AC}_{(\mathrm{x}-1)}+\mathrm{AC}_{(\mathrm{x}-2)}\right)=(17+24+17)=\mathrm{APb}_{(\mathrm{x}-2)}=58 \\
& \left(\mathrm{AC}_{\mathrm{x}}+\mathrm{AC}(\mathrm{x}-1)+\mathrm{AC}(\mathrm{x}-2) \ldots,+\mathrm{AC}_{1}\right)=\mathrm{APb}_{1} \text {; }
\end{aligned}
$$

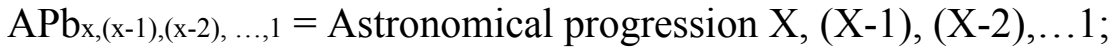

Within the digital pictures in astronomy, the physical and chemical parameters are in a strict compliance with programmatic, cybernetic and information principles. The digital language of astronomy has a countless number of codes and analogue codes, as well as other information content. These pictures enable us to realize the very essence of functioning of astronomical phenomenons (Orbital characteristics, physical characteristics, etc.). There are some examples.

\section{2. Perihelion}

The planets of our solar system have the following Perihelion:

Astronomical progression $\mathrm{APa}$ and $\mathrm{APb}$ (Planets - position from 1 to 8). 
Table 1. Schematic representation of the astronomical progression APa and APb ((Planets position from 1 to 8 ).

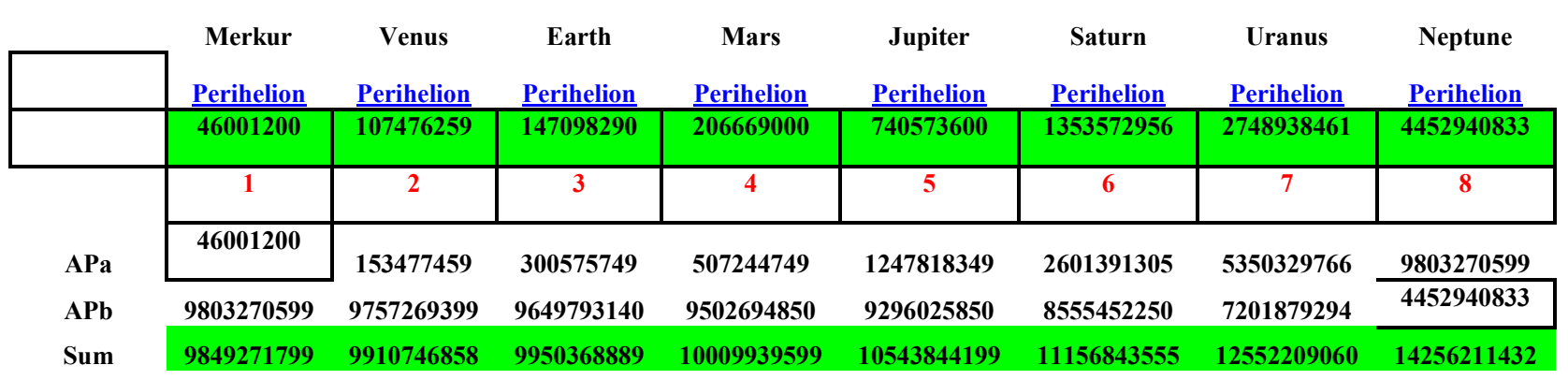

$\mathrm{APa}$ and $\mathrm{APb}$ present astronomical measurements that are used to express the correlation of perihelions of the solar system planets, as well as for the other cosmic bodies. One could tell that these measurements are the codes that interconnect the planets, as well as the other cosmic bodies. Those codes in correlation with each other form a matrix of cosmic codes of perihelions. That matrix is a specific programmatic and information system where some of the orbital characteristics of the solar system planets are projected.

\section{Solar System Planets' Connecting Matrix}

Matrixes $\mathrm{APa}$ and $\mathrm{APb}$ connect all the planets of the solar system, and also determine the path of each of the planets. Here are some examples:

\section{Example 1.}

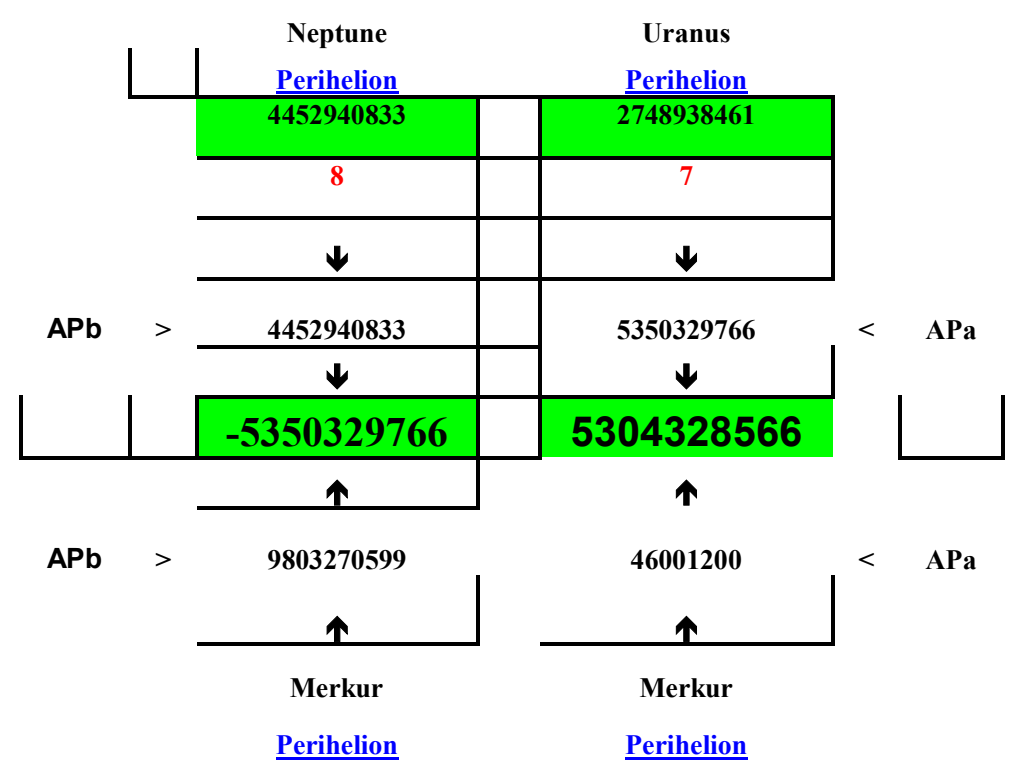

$(4452940833-9803270599)=(-) 5350329766$;

$(5350329766-46001200)=(+) 5350329766$; 
In this example, planets Neptune and Mercury, but also Uranus and Mercury are interconnected by the cosmic code 5304328566. Neptune and Mercury have a negative, and Uranus and Mercury a positive code value. In this way, an exact mathematical balance between positive and negative values of this code is established.

\section{Input:}

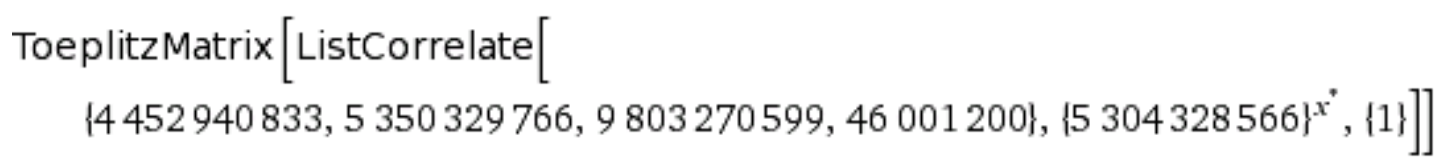

\section{Result:}

$1091807911 \times 2^{x^{*}+1} 3^{x^{*}+2} 884054761^{x^{*}}(1)$

\section{Determinant:}

$1091807911 \times 2^{x^{*}+1} 3^{x^{*}+2} 884054761^{x^{*}}$

\section{Input:}

PadRight ListCorrelate[

$\left.\{4452940833,5350329766,9803270599,46001200\},\{5304328566\}^{x^{*}},\{1\}\right]$

\section{\{PadRight}

$$
\begin{gathered}
\left(1484313611 \times 3^{x^{*}+1} 1768109522^{x^{*}}+2675164883 \times 2^{x^{*}+1} 2652164283^{x^{*}}+\right. \\
\left.\left.2875075 \times 2^{x^{*}+4} 2652164283^{x^{*}}+9803270599 \times 5304328566^{x^{*}}\right)\right\}
\end{gathered}
$$

Interpreting as: ListCorrelate $[\{4452940833,5350329766,9803270599,46001200\}$, $\{5304328566\}^{\wedge}$ Conjugate $\left.[\mathrm{x}],\{1\}\right]$

\section{Input:}

ListCorrelate[

$\left.\{4452940833,5350329766,9803270599,46001200\},\{5304328566\}^{x^{*}},\{1\}\right]$

\section{Result:}

$$
\begin{gathered}
\left\{1484313611 \times 3^{x^{*}+1} 1768109522^{x^{*}}+2675164883 \times 2^{x^{*}+1} 2652164283^{x^{*}}+\right. \\
\left.2875075 \times 2^{x^{*}+4} 2652164283^{x^{*}}+9803270599 \times 5304328566^{x^{*}}\right\}
\end{gathered}
$$




\section{Plots:}
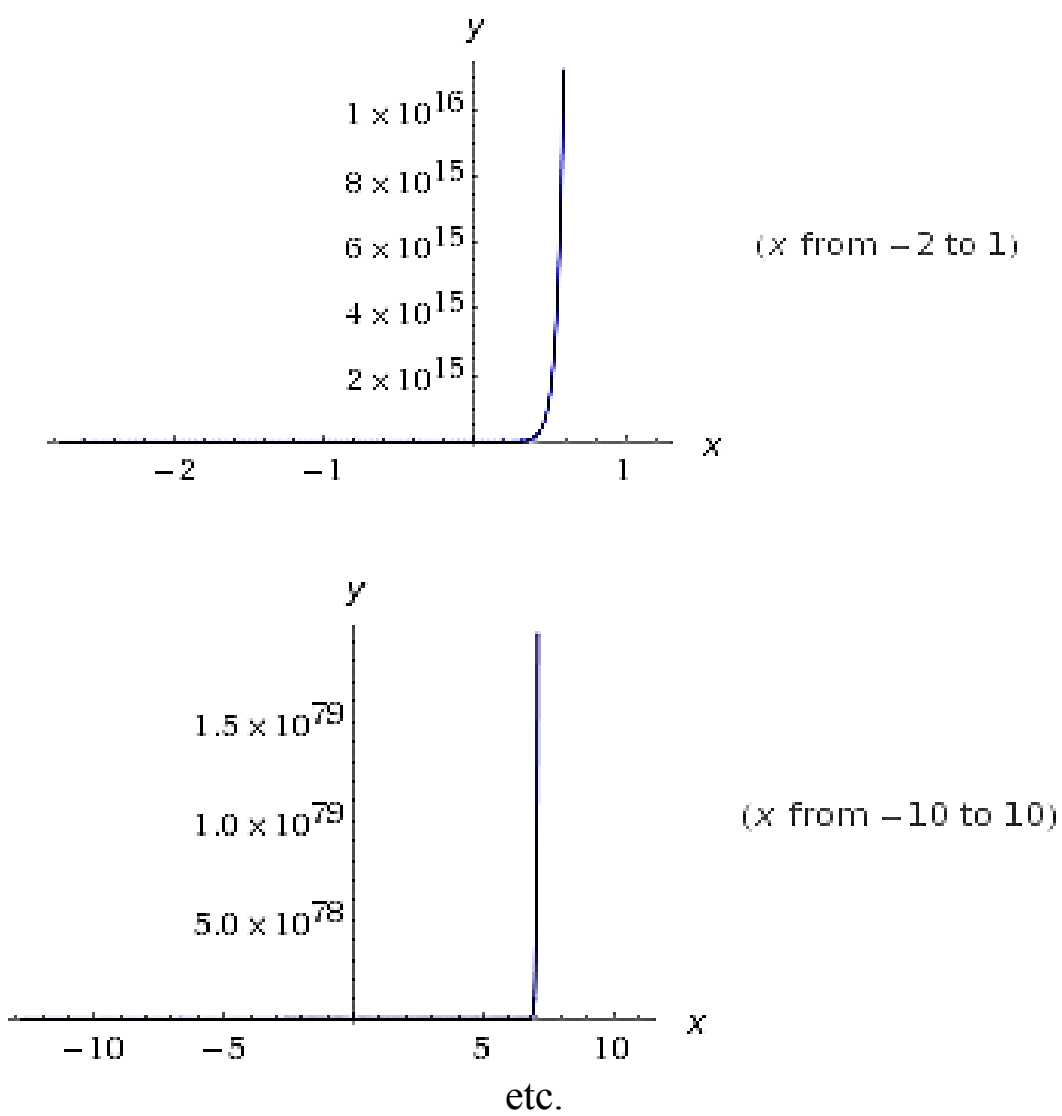

Example 2

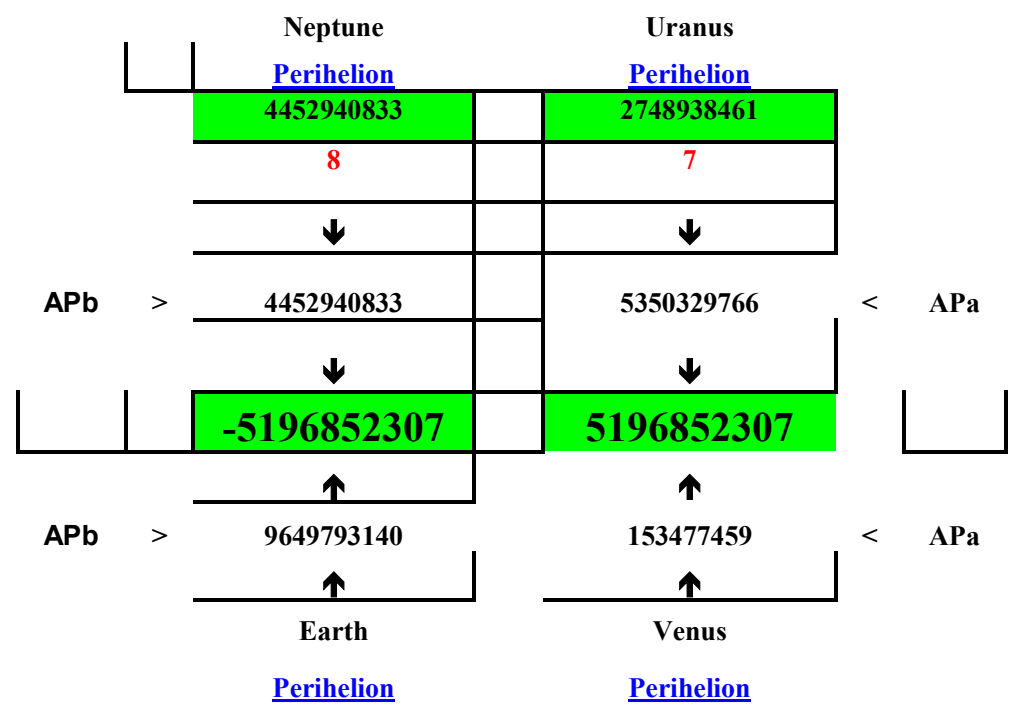

In this example the planets Neptune and Earth, than Uranus and Venus are interconnected through the cosmic code 5196852307. We shall now calculate the difference between the cosmic codes of the planets from the first and the second example: 


$$
(5304328566-5196852307)=107476259
$$

The result is the perihelion of planet Venus. We can say that this perihelion interconnects the mentioned group of planets.

\section{Input:}

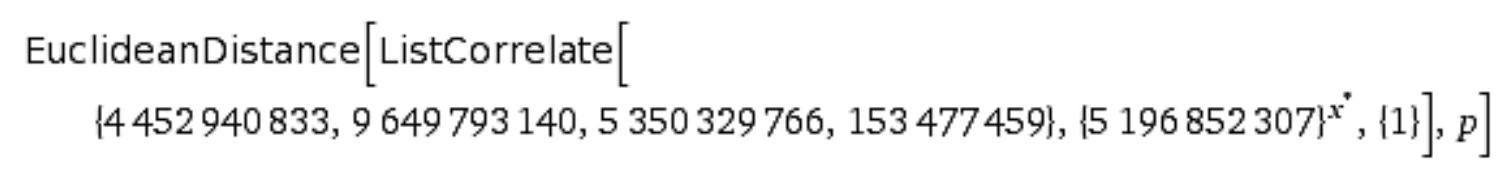

\section{Result:}

$\left|19606541198 \times 5196852307^{x^{*}}-p\right|$

$3 D$ plot:

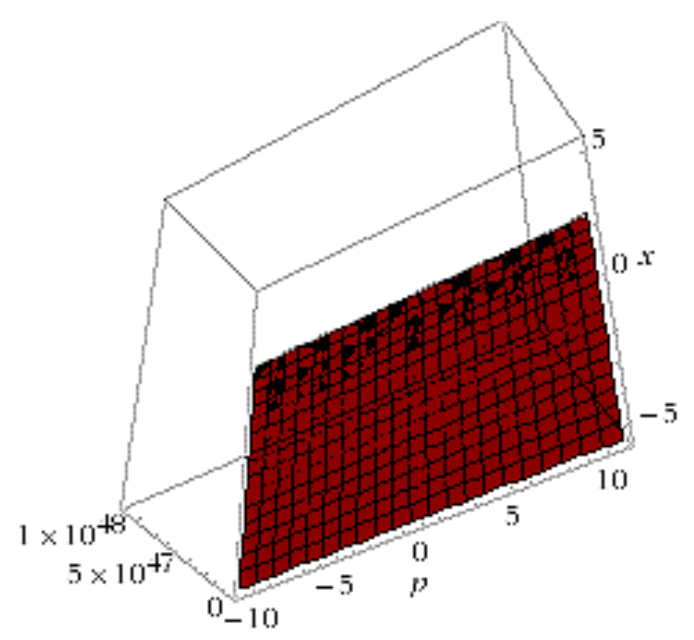

Contour plot:

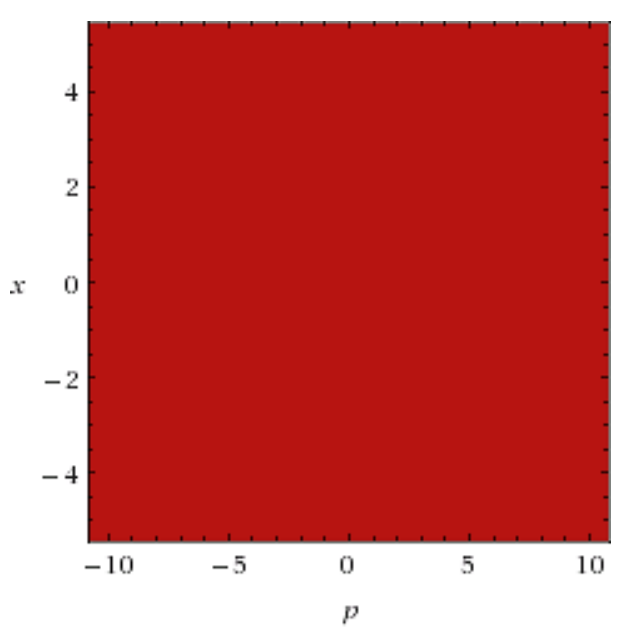


Alternate form assuming $p$ and $x$ are positive: $\left|19606541198 \times 5196852307^{x}-p\right|$

Alternate form assuming $p$ and $x$ are positive:

$$
\left|p-19606541198 \times 5196852307^{x}\right|
$$

\section{Alternate form assuming $p$ and $x$ are real:}

$$
\sqrt{\left(19606541198 \times 5196852307^{x}-p\right)^{2}}
$$

$d^{\wedge} 2 / d x^{\wedge} 2$ EuclideanDistance(ListCorrelate(\{4452940833, 9649793140, 5350329766, $153477459\},\{5196852307\}^{\wedge}\left(x^{\wedge}\right.$ conjugate $\left.\left.),\{1\}\right), p\right)$

\section{Derivative:}

$$
\begin{aligned}
& \frac{\partial^{2}}{\partial x^{2}}(\text { EuclideanDistance [ListCorrelate }[14452940833,9649793140, \\
& \left.\left.\left.5350329766,153477459\},\{5196852307\}^{x^{x^{*}}},\{1\}\right], p\right]\right)= \\
& \left(19606541198 \times 5196852307^{x^{x^{*}}}\left(19606541198 \times 5196852307^{x^{x^{*}}}-p\right) x^{x^{*}-2}\right. \\
& \log (5196852307)\left(x^{*}\left(2 x \log (x) \operatorname{Conjugate}^{\prime}(x)\left(\log (5196852307) x^{x^{*}}+1\right)-1\right)+\right. \\
& x\left(x \log (x) \text { Conjugate }{ }^{\prime \prime}(x)+x \log ^{2}(x) \text { Conjugate }^{\prime}(x)^{2}\right. \\
& \left.\left(\log (5196852307) x^{x^{*}}+1\right)+2 \text { Conjugate }^{\prime}(x)\right)+ \\
& \left(\sqrt{\left(p-19606541198 \times 5196852307^{x^{x^{*}}}\right)^{2}}\right)
\end{aligned}
$$

integrate EuclideanDistance(ListCorrelate $\{$ 4452940833, 9649793140, 5350329766, $153477459\},\{5196852307\}^{\wedge}\left(x^{\wedge}\left(x^{\wedge}\right.\right.$ conjugate $\left.\left.\left.)\right),\{1\}\right), p\right) d x$

\section{Input:}

$$
\begin{aligned}
& \int \text { EuclideanDistance }[ \\
& \text { ListCorrelate }[\{4452940833,9649793140,5350329766,153477459\}, \\
& \left.\left.\{5196852307\}^{x^{x^{x^{*}}}},\{1\}\right], p\right] d x
\end{aligned}
$$


series of EuclideanDistance(ListCorrelate $(\{4452940833,9649793140,5350329766$,

$153477459\},\{5196852307\}^{\wedge}\left(x^{\wedge}\left(x^{\wedge}\left(x^{\wedge}\right.\right.\right.$ conjugate $\left.\left.\left.\left.)\right)\right),\{1\}\right), p\right)$ at $x=0$ :

\section{Input interpretation:}

\begin{tabular}{|l|l|l|l|}
\hline series & $\begin{array}{l}\text { EuclideanDistance[ListCorrelate }[ \\
\{4452940833,9649793140,5350329766,\end{array}$ & point & $x=0$ \\
& $153477459\},\{5196852307\}^{\left.\left.x^{x^{x^{x^{*}}}},\{1\}\right], p\right]}$ & \\
\hline
\end{tabular}

\section{Series representations:}

$$
\begin{aligned}
& \left|19606541198 \times 5196852307^{x^{x^{x^{*}}}}-p\right|= \\
& \frac{2}{\pi}-\frac{4 \sum_{k=1}^{\infty} \frac{(-1)^{k} T_{2 k}\left(19606541198 \times 5196852307^{x^{x^{x^{*}}}}-p\right)}{-1+4 k^{2}}}{\pi} \\
& \text { for }\left(19606541198 \times 5196852307^{x^{x^{x^{*}}}}-p \in \mathbb{R}\right. \text { and } \\
& \left.-1<19606541198 \times 5196852307^{x^{x^{x^{*}}}}-p<1\right)
\end{aligned}
$$

$$
\begin{aligned}
& \left|19606541198 \times 5196852307^{x^{x^{x^{*}}}}-p\right|=
\end{aligned}
$$

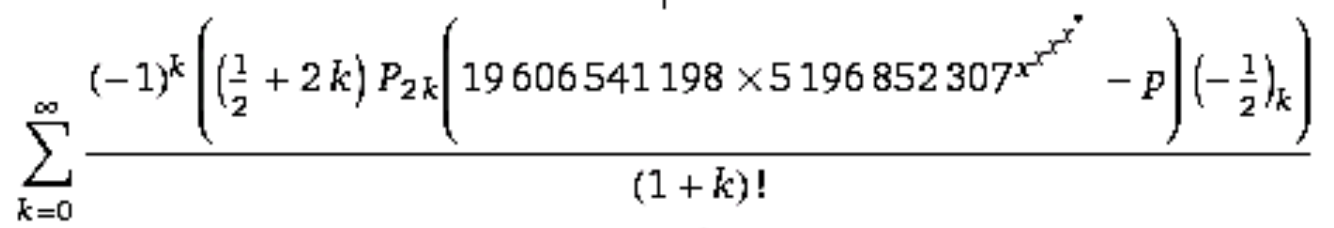

$$
\begin{aligned}
& \text { for }\left(19606541198 \times 5196852307^{x^{x^{x^{*}}}}-p \in \mathbb{R}\right. \text { and } \\
& \left.-1<19606541198 \times 5196852307^{x^{x^{x^{*}}}}-p<1\right)
\end{aligned}
$$




$$
\begin{aligned}
& \left|19606541198 \times 5196852307^{x^{x^{x^{*}}}}-p\right|=
\end{aligned}
$$

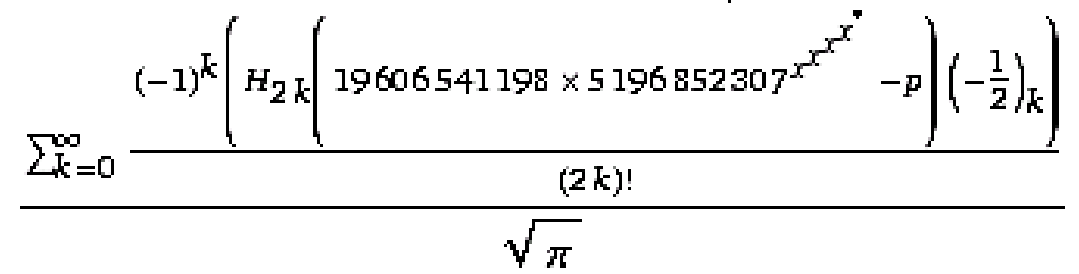

$$
\begin{aligned}
& \text { for }\left(19606541198 \times 5196852307^{x^{x^{x^{x^{*}}}}}-p \in \mathbb{R}\right. \text { and } \\
& \left.-1<19606541198 \times 5196852307^{x^{x^{x^{*}}}}-p<1\right)
\end{aligned}
$$

$|z|$ is the absolute value of $z$

$T_{n}(x)$ is the Chebyshev polynomial of the first kind

$R$ is the set of real numbers

$n$ ! is the factorial function

$P_{n}(x)$ is the Legendre function of the first kind

$(a)_{n}$ is the Pochhammer symbol

$H_{n}(x)$ is the $n^{\text {th }}$ Hermite polynomial in $x$

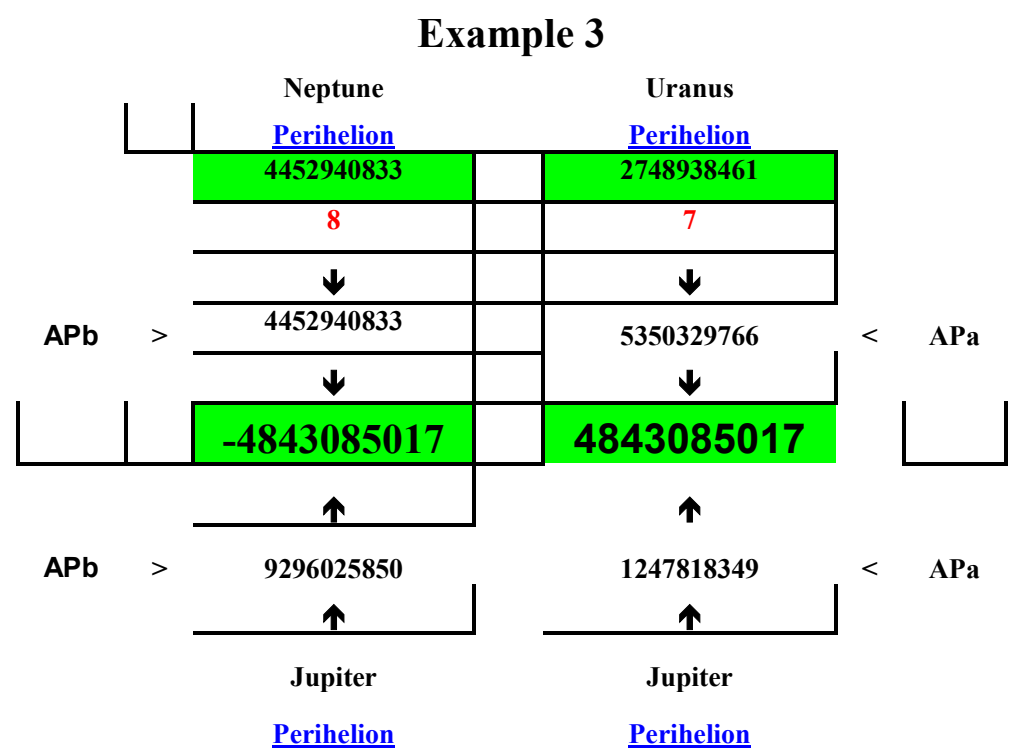

In this example the planets Neptune and Jupiter, also Uranus and Jupiter, are interconnected through the 4843085017 code. Let us now calculate the difference between the codes of groups of planets from thesecond and third example:

$$
(5196852307-4843085017)=353767290 ;
$$


Therefore, these groups of planets are interconnected through the 353767290 code. This code, actually this number, interconnects the following groups of planets:

\section{Example 4}

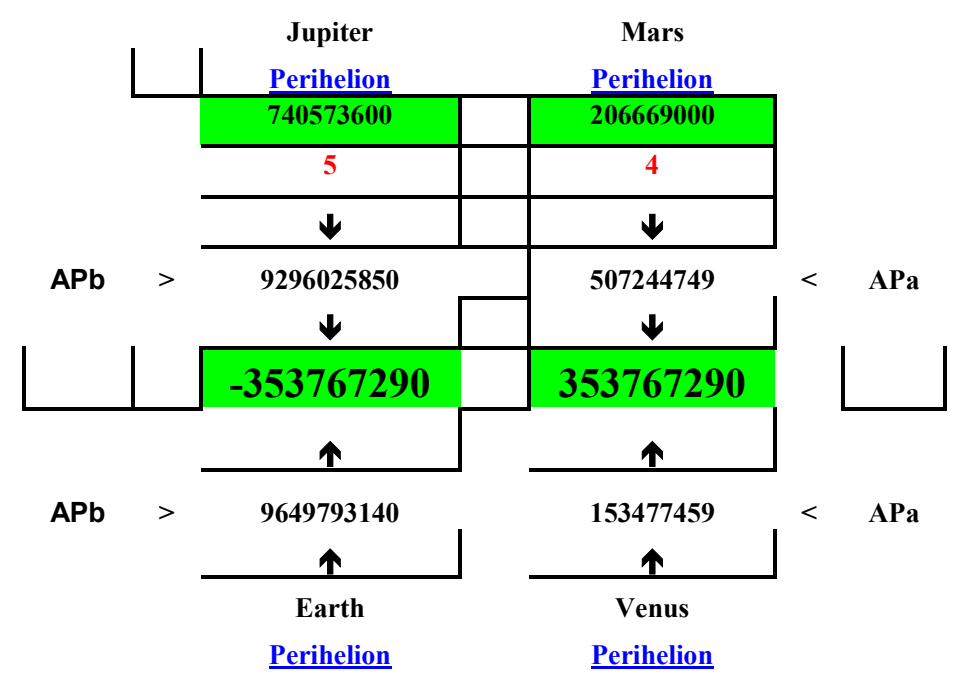

The cosmic code from this example, which is the number 353767290 , interconnects the group of planets from the fourth example with the groups of planets from the second and third example.

\section{Example 5}

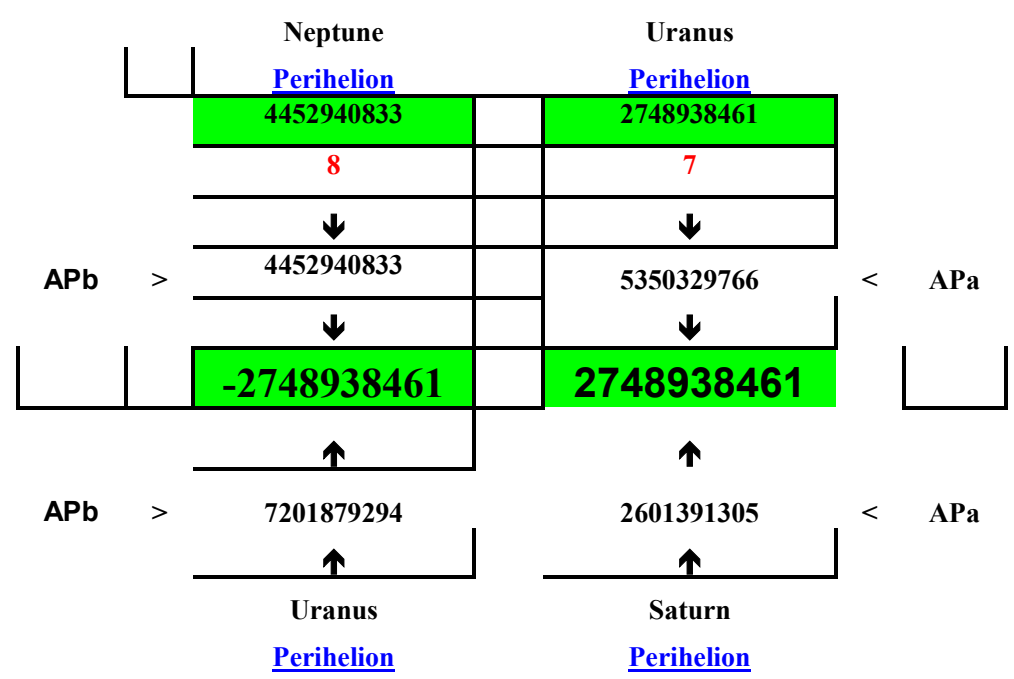

Code 2748938461 interconnects planets Neptune and Uranus with planets Uranus and Saturn. 


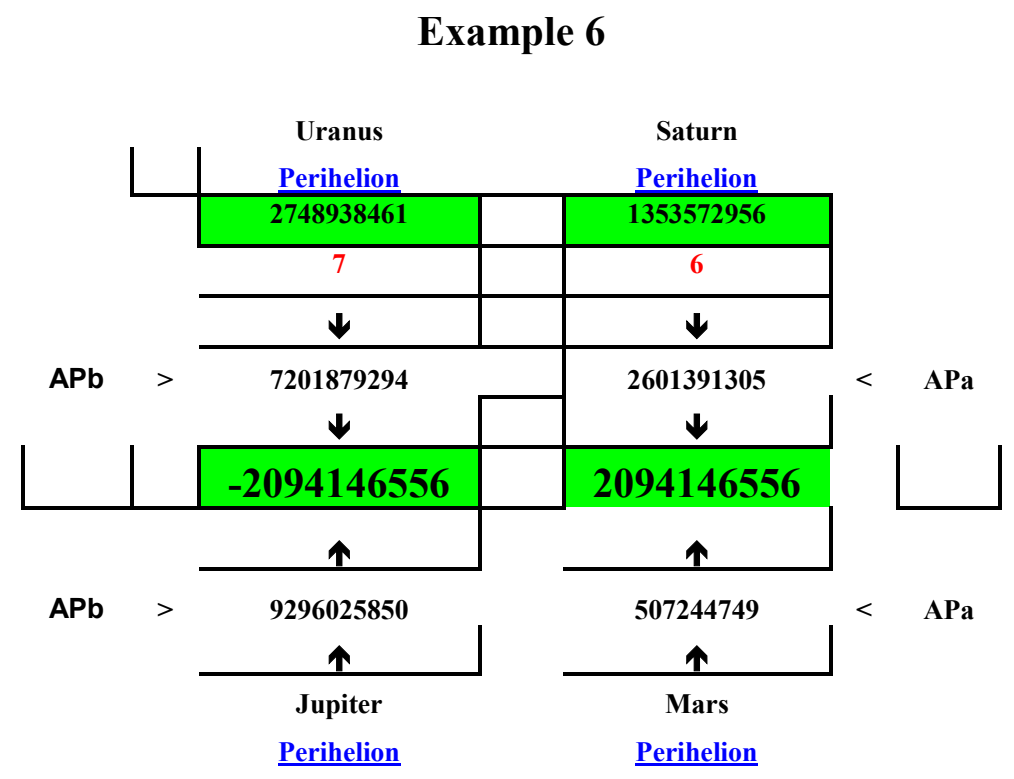

Code 2094146556 interconnects planets Uranus and Jupiter with planets Mars and Saturn. That code represents the difference between the cosmic codes from the third and fifth groups of planets.

$$
(4843085017-2748938461)=2094146556
$$

- In this example, connection between codes from the third, fifth and sixth groups of planets has been established.

\section{Example 7}

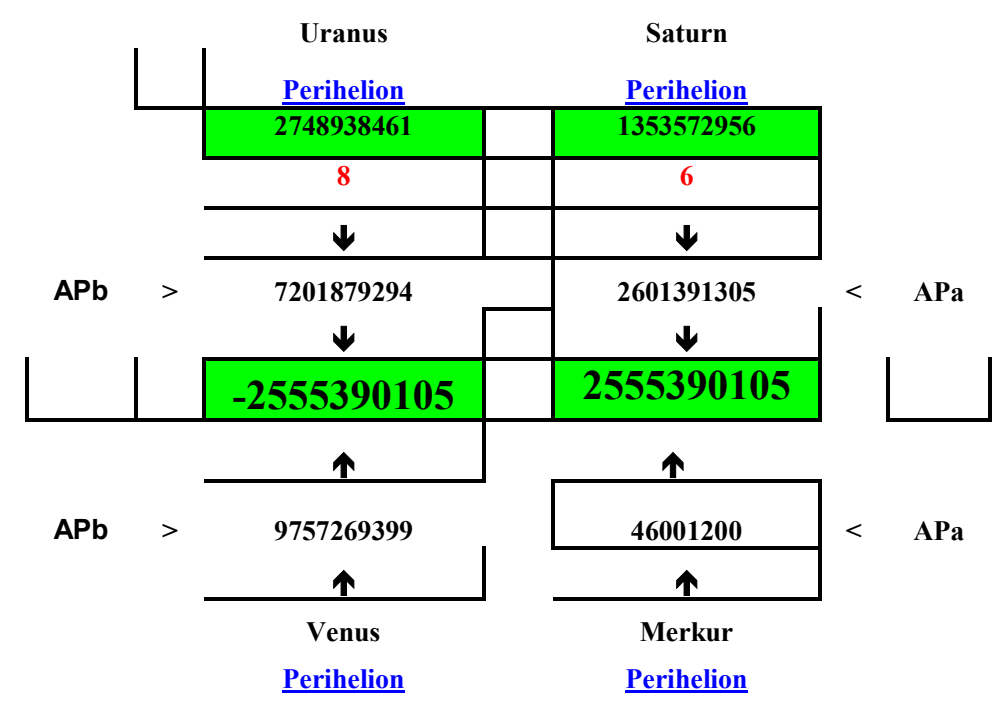

Code 2555390105 connects planets Uranus and Venus with planets Saturn and Mercury.

Code 2555390105 is connected with cosmic codes from the first and fifth groups of planets:

$(5304328566-2748938461)=2555390105$; 
Therefore, there is a mathematical connection between the first, fifth and seventh groups of planets. The difference between the codes of the first and seventh groups of planets is number: 2748938461 , and that number is the perihelion of the planet Uranus. This means that the firstand seventh groups of planets are interconnected by the perihelion of Uranus.

$$
(5304328566-2555390105)=2748938461 ;
$$

\section{Example 8}

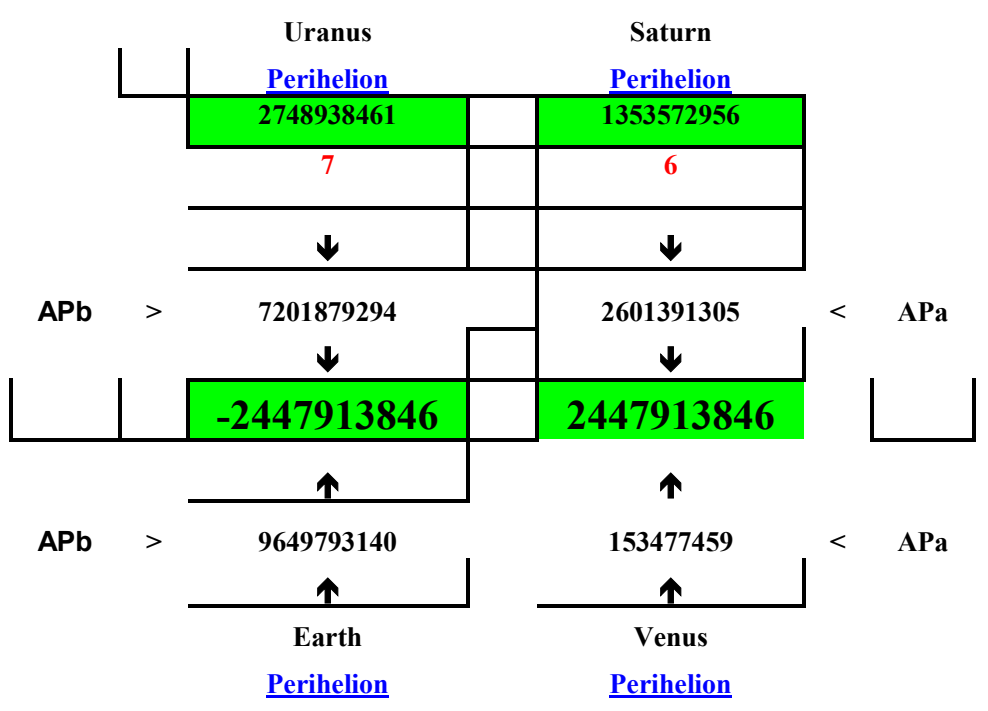

The difference of cosmic codes between the seventh and eighth groups of planets is the perihelion of planet Venus:

$$
(2555390105-2447913846)=107476259
$$

The difference of cosmic codes between the seventh and eighth groups of planets is equal to the difference of codes between the first and second groups of planets.

$$
(2555390105-2447913846)=(5304328566-5196852307) \text {; }
$$

The difference of cosmic codes between the seventh and eighth groups of planets is 107476259. This difference is the code that connects the following planets:

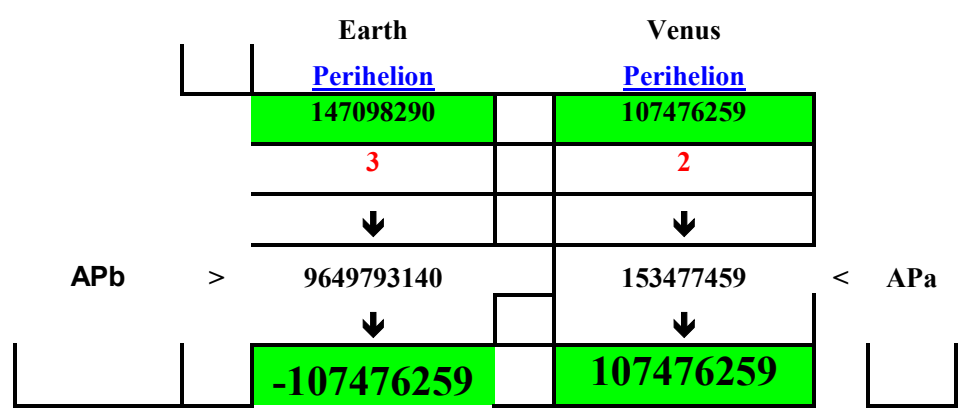




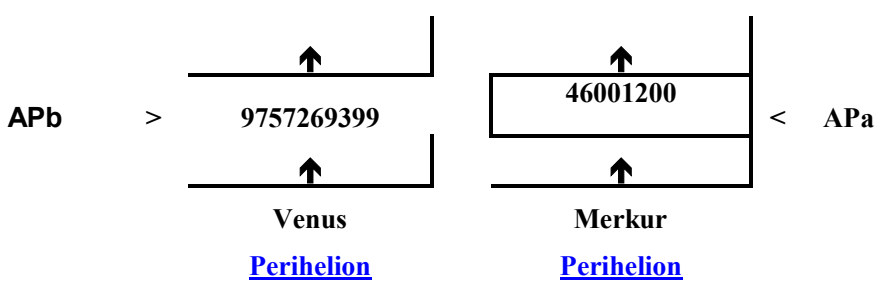

The difference of cosmic codes between the seventh and eighth groups of planets connects the following planets: Earth and Venus, and Venus and Mercury.

The difference of cosmic codes between the eighth and six th groups of planets results in the cosmic code of the fourth group of planets, which is the number 353767290 ;

$$
(2447913846-2094146556)=353767290
$$

The difference of cosmic codes between the eighth and fourth groups of planets results in the cosmic code of the sixth group of planets:

$$
(2447013846-353767290)=2094146556 ;
$$

\section{Example 9}

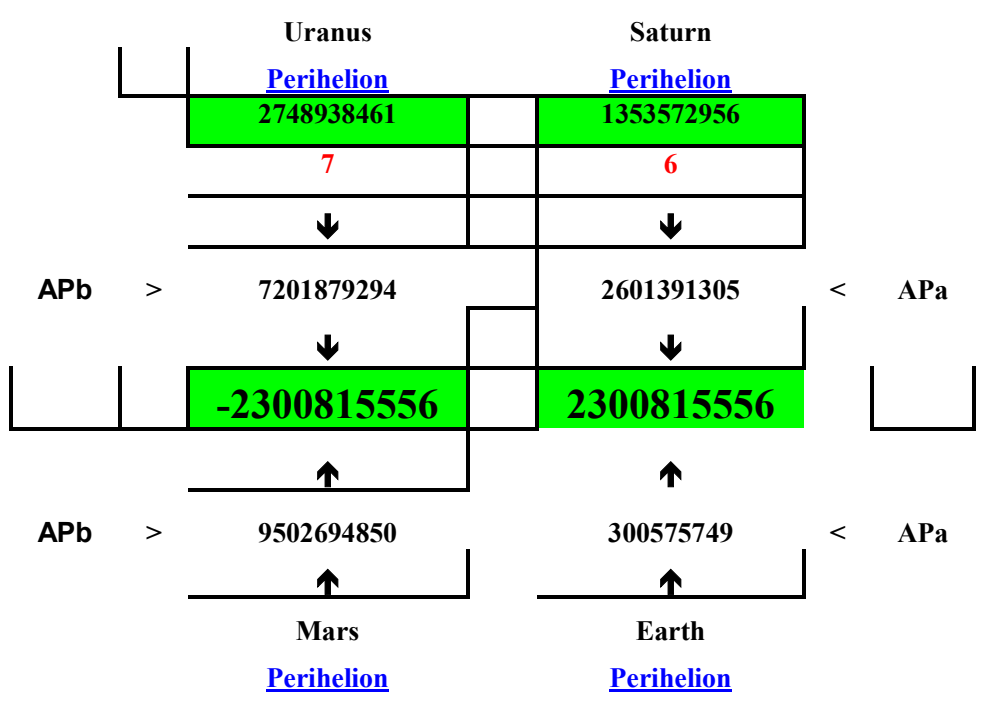

Code 2300815556 connects planets Uranus and Mars with planets Saturn and Earth. The difference of cosmic codes between the eighth and ninth groups of planets results in the perihelion of planet Earth:

$$
(2447913846-2300815556)=147098290
$$

- Perihelion of planet Earth connects planets Mars and Earth, also Earth and Venus. 


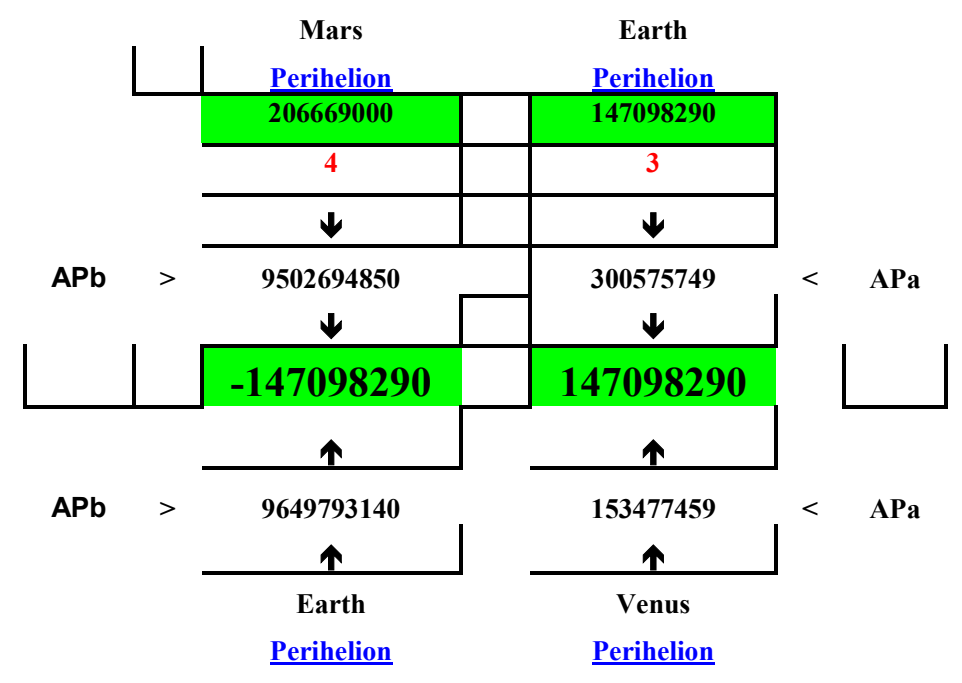

Perihelion of planet Earth is 147098290 , and as it can be observed that code really connects the following planets: The difference of cosmic codes between the ninth and sixth groups of planets results in the perihelion of planet Mars:

$$
(2300815556-2094146556)=206669000
$$

Perihelion of Mars is 206669000;

Perihelion of Mars, through cosmic codes, connects the following planets: Jupiter and Mars, also Mars and Earth. Here is the example:

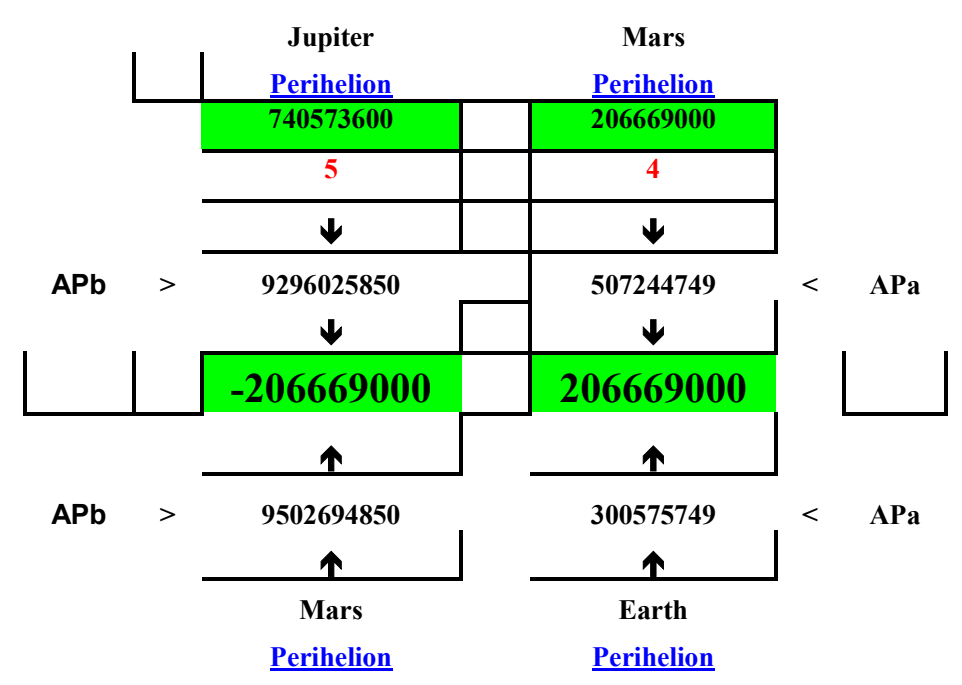




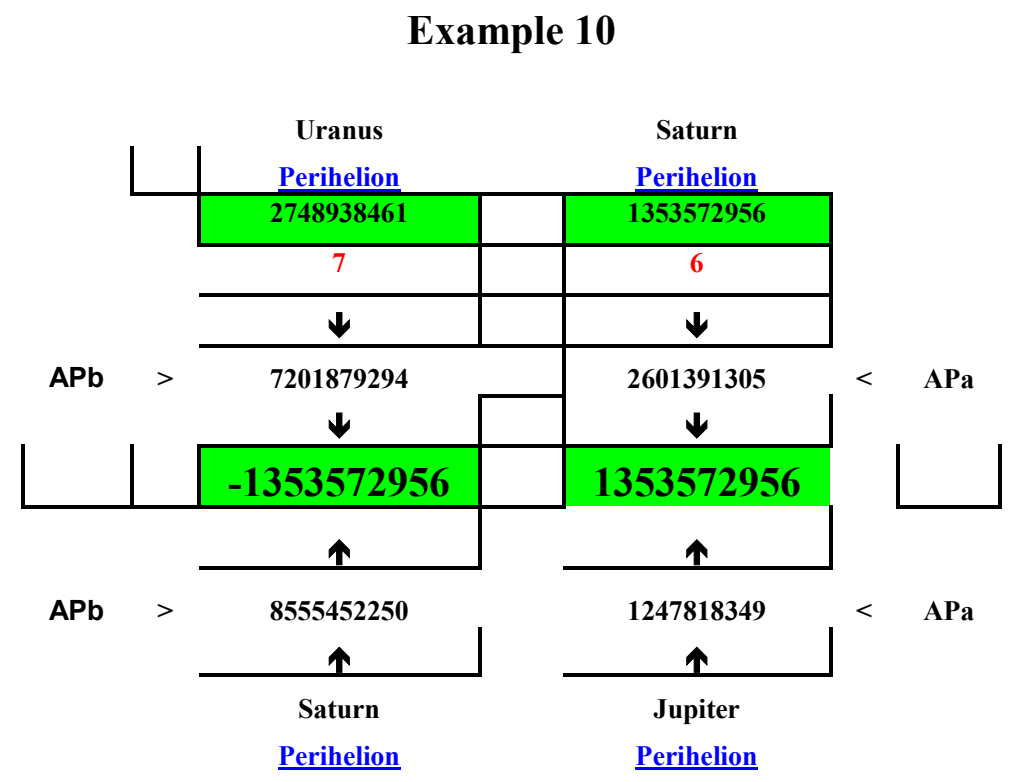

Code 1353572956 connects planets Uranus and Saturn, also Saturn and Jupiter.

The mentioned code is actually the perihelion of planet Saturn, therefore it can be said that perihelion connects these planets. The difference of cosmic codes between the ninth and this tenth group of planets results in the cosmic code 947242600.

$$
(2300815556-1353572956)=947242600 \text {; }
$$

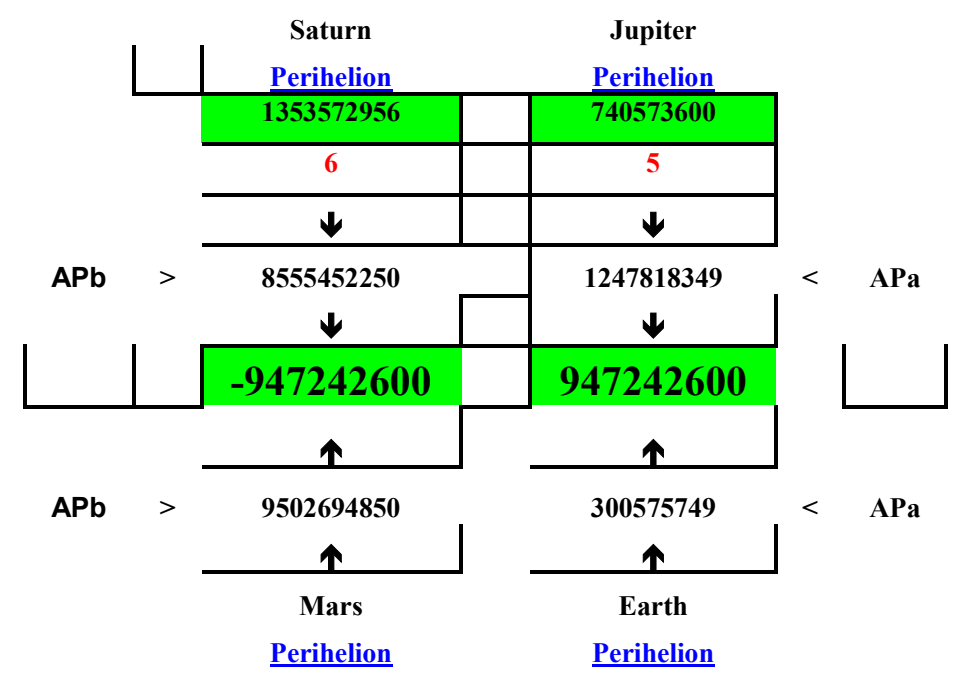

In this example code 9477242600 connects planets Saturn and Mars, also Jupiter and Earth. The difference of cosmic codes between the tenth and seventh group of planets results in the cosmic code 1201817149 . Here is the example: 


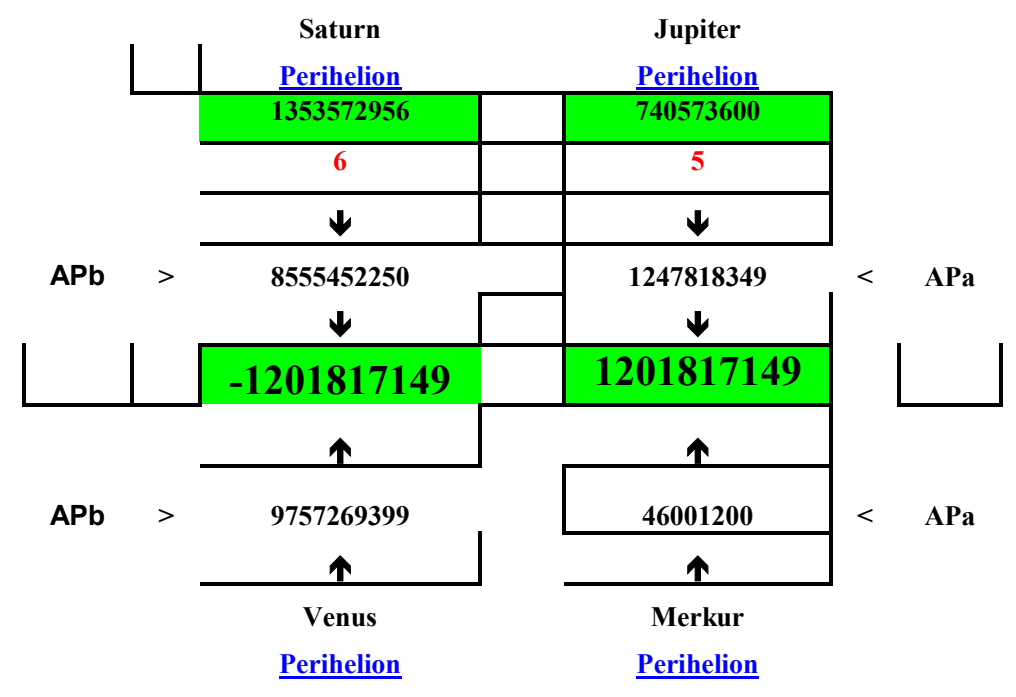

In this example code 1201817149 connects planets Saturn and Venus, also Jupiter and Merkur. The difference of cosmic codes between the sixth and tenth group of planets results in the perihelion of planet Jupiter:

$$
(2094146556-1353572956)=740573600 \text {; }
$$

Perihelion of Jupiter is 740573600 ;

Perihelion of Jupiter, through cosmic codes, connects the following planets: Saturn, Jupiter, also Jupiter and Mars.

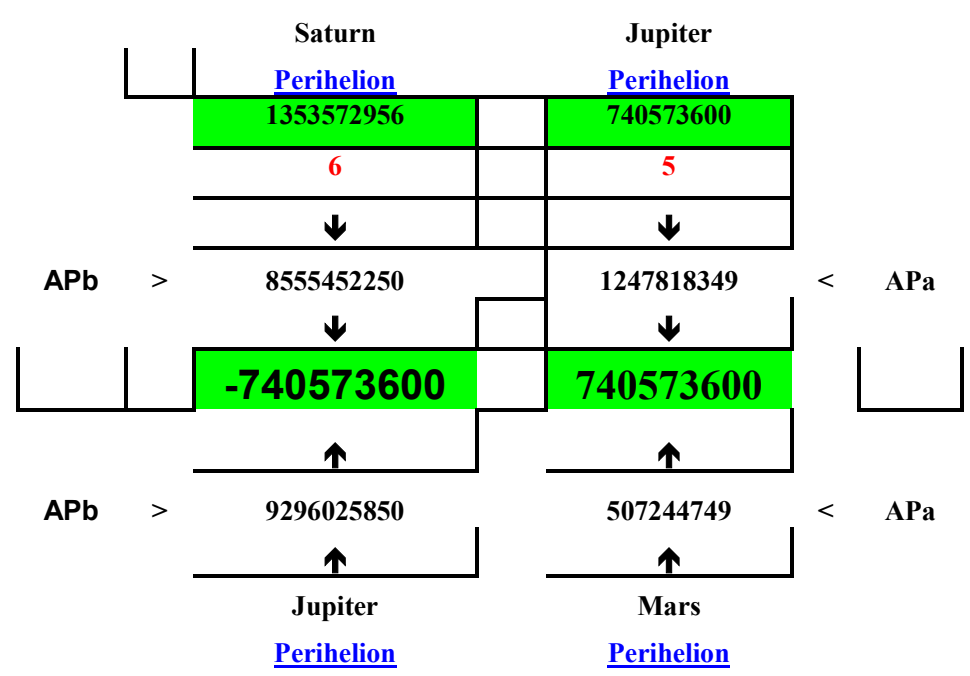




\section{Example 11}

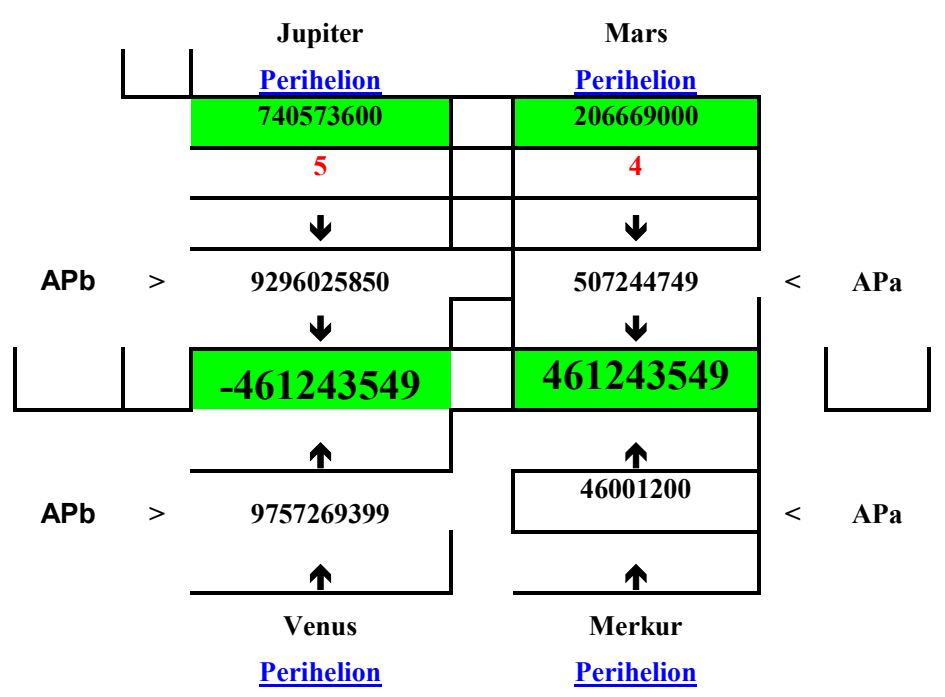

Code 461243549 connects the following planets: Jupiter and Venus, also Mars and Mercury.

\section{Example 12}

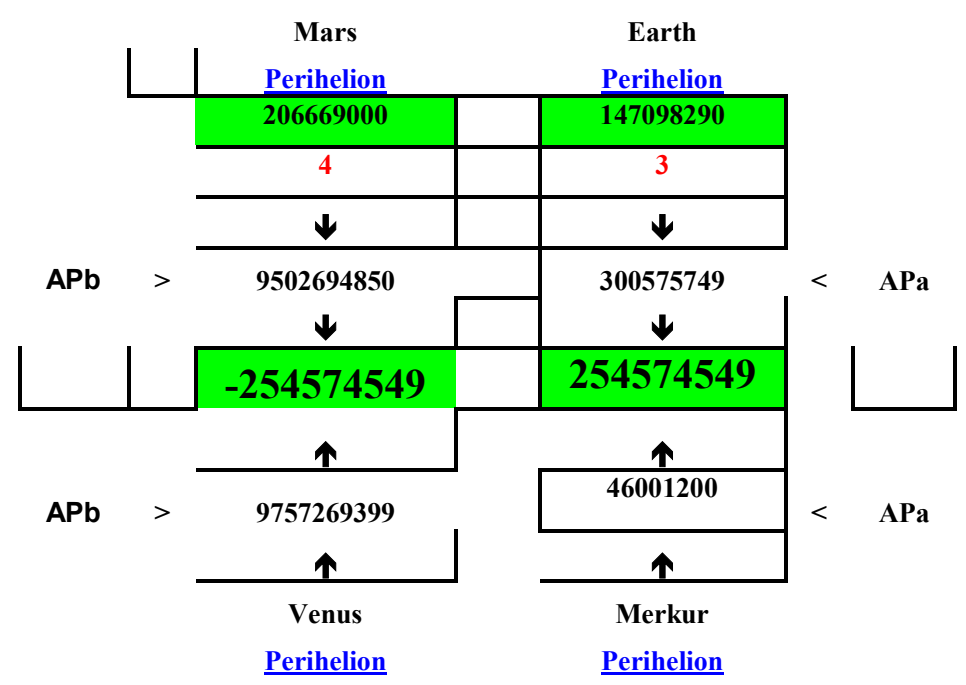

Code 254574549 connects the following planets: Mars and Venus, also Earth and Merkur. There are many more similar examples. As we can see, the paths of planets of the solar system are connected through many cosmic codes. These codes determine the path that each planet has to follow, its perihelion and aphelion, as well as other characteristics of their orbits.

table $\mathrm{d}^{\wedge} \mathrm{n} / \mathrm{dp}^{\wedge} \mathrm{n}$ EuclideanDistance(ListCorrelate $(\{\mathbf{9 5 0 2 6 9 4 8 5 0}, 9757269399, \mathbf{3 0 0 5 7 5 7 4 9}$, 46001200 $\},\{\mathbf{2 5 4 5 7 4 5 4 9}\} \wedge\left(\mathrm{x}^{\wedge}\left(\mathrm{x}^{\wedge}\left(\mathrm{x}^{\wedge}\left(\mathrm{x}^{\wedge}\left(\mathrm{x}^{\wedge}\left(\mathrm{x}^{\wedge}\right.\right.\right.\right.\right.\right.$ conjugate $\left.\left.\left.\left.\left.\left.)\right)\right)\right)\right),\{1\}\right), \mathrm{p}\right)$ for $\mathrm{n}=1 \ldots 4$ 


\section{Input interpretation:}

Table [

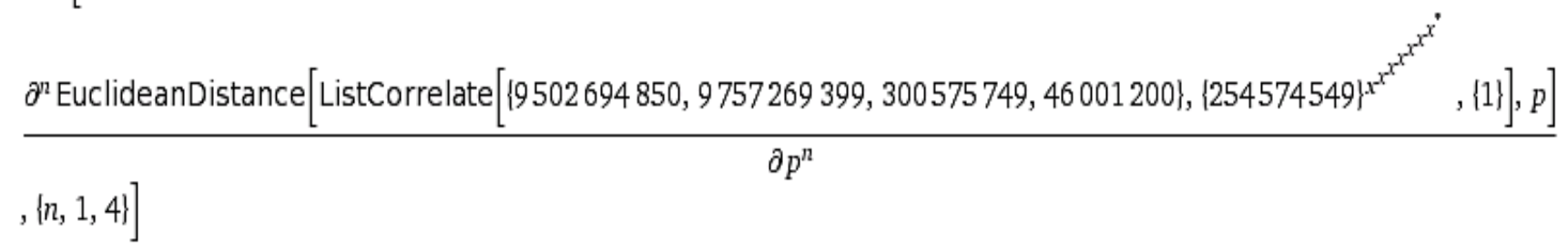

\section{Result:}

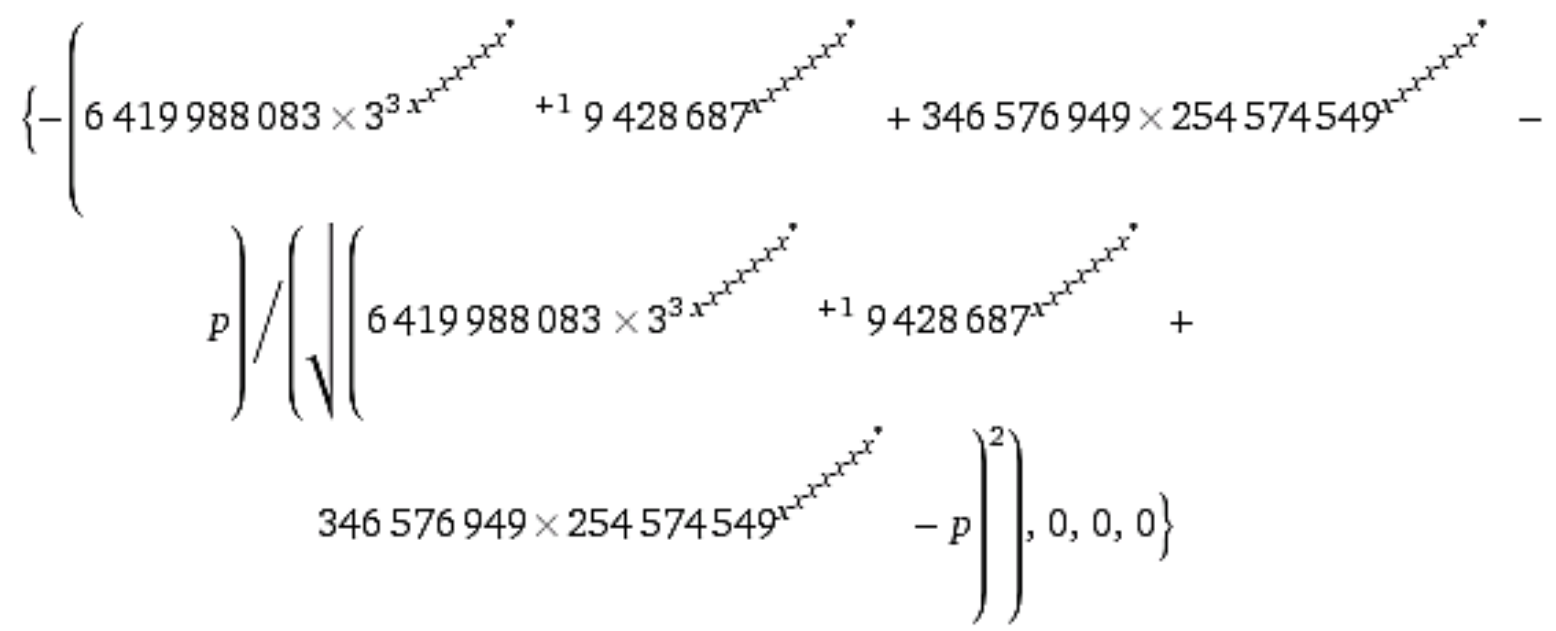

$\mathrm{d}^{\wedge} 3 / \mathrm{dp}^{\wedge} 3$ EuclideanDistance(ListCorrelate $(\{9502694850,9757269399,300575749$, $46001200\},\{254574549\}^{\wedge}\left(\mathrm{x}^{\wedge}\left(\mathrm{x}^{\wedge}\left(\mathrm{x}^{\wedge}\left(\mathrm{x}^{\wedge}\left(\mathrm{x}^{\wedge}\left(\mathrm{x}^{\wedge}\left(\mathrm{x}^{\wedge}\right.\right.\right.\right.\right.\right.\right.$ conjugate $\left.\left.\left.\left.\left.\left.\left.)\right)\right)\right)\right)\right),\{1\}\right), \mathrm{p}\right)$

\section{Derivative:}

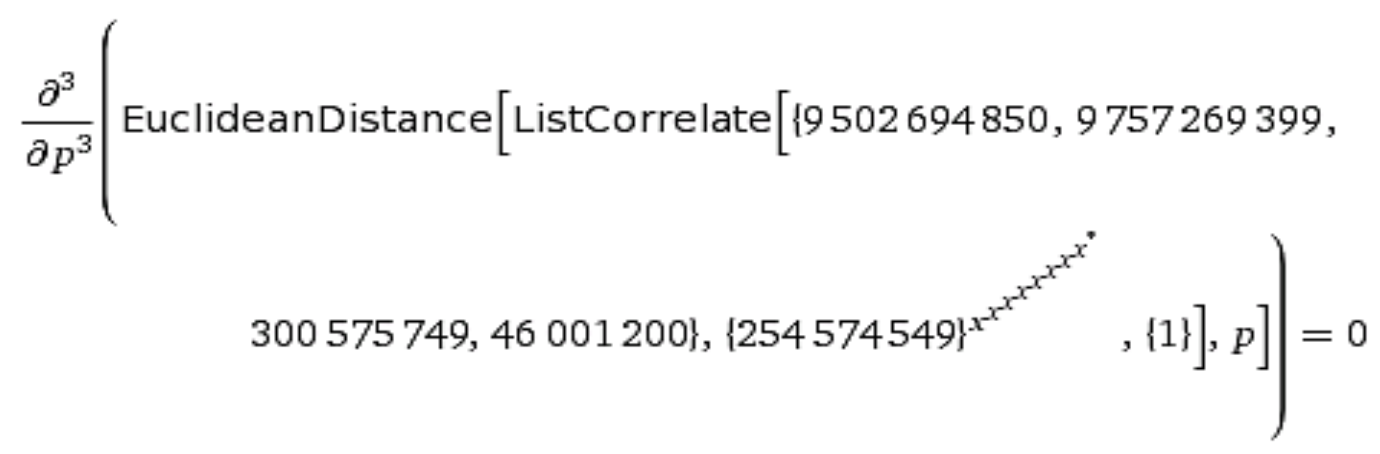

etc. 


\section{CONCLUSIONS}

As we see, the Solar System code is itself a unique structure of program, cybernetic and informational system and law. The research we carried out have shown that astronomical progression are one of quantitative characteristics in astronomy. Astronomical progression is, actually, a discrete code that protects and guards planetary information coded in Solar System. This a recently discovered code, and more detailed knowledge on it is yet to be discovered. In a similar way we shall calculate astronomical codes of other unions of panets. Once we do this, we will find out that all these unions of planets are connected by various codes, analogue codes as well as other quantitative features.

In the previous examples we translated the Orbital characteristics from the language of astronomy into the digital language of programmatic, cybernetic and information principles. This we did by using the adequate mathematical algorithms. These digital pictures reveal to us a whole new dimension of this science. They reveal to us that the astronomical phenomenons are strictly conditioned and determined by programmatic, cybernetic and information principles.

From the previous examples we can see that Solar System really has its quantitative characteristics. It can be concluded that there is a connection between quantitative characteristics in the process of transfer of orbital information and the qualitative appearance of given astronomical phenomenons.

\section{References}

[1] L. Kurić, International Letters of Chemistry, Physics and Astronomy 10 (2014) 62-73.

[2] L. Kurić, J. Comput Sci Biol 2 (2009) 101-116.

[3] L. Kurić, Journal de la Societe de statistique de Paris 127(2) (1986).

[4] L. Kurić, GJMR 10(1) (2010) 15.

[5] L. Kurić, Advances and Applications in Bioinformatics and Chemistry 2010, $45-58$.

[6] L. Kurić, GJMR 1(1) (2010) 15.

[7] L. Kurić, International Journal of Computer Technology and Application 2(2) (2011) 216-241.

[8] L. Kurić, International Journal of Computer Technology and Application 2(2) (2011) 258-273.

[9] L. Kurić, Journal of Chemical Enginerring and Material Science 2(5) (2011).

[10] L. Kurić, International Letters of Chemistry, Physics and Astronomy 11(3) (2014) 202-213. 